\title{
PRÁTICAS CORPORAIS NAS ESCOLAS DE ENSINO MÉDIO SITUADAS EM VITÓRIA/ESPÍRITO SANTO
}

\author{
Gabriel Carvalho Bungenstab \\ Universidade Federal de Goiás, Goiânia, Goiás, Brasil \\ Felipe Quintao de Almeida \\ Universidade Federal do Espírito Santo, Vitória, Espírito Santo
}

\begin{abstract}
Resumo
O artigo aborda a relação que os jovens do Ensino Médio estabelecem com as práticas corporais realizadas por eles dentro e fora da escola. Para tal, a pesquisa envolveu todas as escolas estaduais que ofertam o Ensino Médio na cidade de Vitória, Capital do Espírito Santo (ES). A aplicação de um questionário ofereceu indícios de como os jovens se relacionam com o saber da educação física e das diferentes práticas corporais. Conclui que os jovens demonstram que as práticas corporais escolares ficam, muitas vezes, aquém de suas expectativas. No entanto, notou-se, também, que não há uma desvalorização dessas práticas em relação àquelas que são realizadas fora da escola.
\end{abstract}

Palavras-chave: Práticas corporais. Ensino Médio. Juventude.

\section{Introdução}

A escola apresenta-se como um lugar de aprendizagem. A educação física, como disciplina constituinte do currículo escolar, é permeada por conteúdos específicos (ALMEIDA JUNIOR et al. 2006). Na esteira de Fensterseifer (2012), consideramos que os conteúdos dessa disciplina fazem parte do universo da cultura corporal de movimento (CCM). Dentro deste universo situam-se as práticas corporais e essas, de acordo com Silva et al. (2009), são fenômenos no âmbito corporal que se constituem como manifestações culturais. Tal ideia é corroborada, também, por Lazzarotti Filho et al. (2009). Para esses autores, as práticas corporais se desvencilham dos fins utilitaristas e proporcionam outras dimensões que são minimamente exploradas, como a relação com o outro, as emoções e os elementos da natureza.

Os modos que os jovens ${ }^{1}$ vivem e se expressam corporalmente são percebidos tanto dentro da instituição escolar como fora dela. Seja em um campinho de terra ou participando de uma aula de educação física eles mantém relações de aprendizagens e experiências com as práticas corporais. Nesse sentido, como se dá a relação das práticas corporais que são realizadas dentro da escola se comparadas com aquelas que são realizadas fora dela? Será que os jovens possuem preferência de localidade para realizar determinadas práticas?

De acordo com Fensterseifer (2012), há uma diferença entre a escola e o seu mundo exterior. Mesmo que ela quisesse reproduzir o mundo em seu interior, ela nunca conseguiria tal feito e, no máximo, criaria o "mundo da escola", mas nunca completamente o "mundo na escola". A hipótese deste artigo é a de que as práticas corporais realizadas fora da escola estão

\footnotetext{
${ }^{1}$ Corroboramos, na esteira de Dayrell (2003), Abramo (1997) e Pais (1993), com a ideia de diferentes juventudes. Entende-se que, de acordo com o local, a posição social e situação econômica, os jovens vivem suas juventudes de formas diferentes.
} 
mais presentes na vida dos estudantes, já que vivemos em um mundo (BERMAN, 2007) no qual o jovem tem a possibilidade de experimentar e vivenciar as mais diversas práticas corporais. A escola e a disciplina de educação física, por sua vez, não conseguem "competir" com esta intensa oferta de práticas corporais e, assim, correm o risco de acabarem se tornando espaços sem sentido para os jovens estudantes de Ensino Médio.

$\mathrm{O}$ intuito deste texto ${ }^{2}$ foi o de mapear as práticas corporais que a juventude capixaba (especificamente a situada na capital Vitória) tem acessado dentro da escola (nas aulas de educação física) e, também, suas experiências com práticas corporais fora dela. Assim, foi aplicado um questionário aberto a 276 jovens em todas as escolas visitadas (no total de 13) de Ensino Médio. Vale a pena salientar que a análise dos dados foi feita por meio da técnica de análise de conteúdos. Como bem já ressaltaram Bardin (1988) e Trivinos (1987), a análise de conteúdo possui como função interpretar os sentidos atribuídos às comunicações e as mensagens (escritas ou não) surgidas durante o processo investigativo.

Três são as etapas básicas no processo do uso de análise de conteúdo, a saber: préanálise, exploração do material e interpretação dos dados. Respeitando estas etapas o texto está organizado em três momentos. No primeiro deles (composto pela metodologia e pela seleção dos sujeitos), descrevemos o resultado do levantamento feito nas 13 escolas da Capital, tomando como base as visitas, as anotações do diário de campo e as informações disponíveis no site da Secretaria de Educação do Espírito Santo (SEDU). Além disso, também justificamos a opção em pesquisar os 276 jovens. Já o segundo momento do texto é dedicado à apresentação e a análise dos resultados, primeiramente discutindo o vínculo dos estudantes com a escola e, depois, analisando a relação deles com as práticas corporais e a disciplina de educação física. Na sequência, a conclusão do texto.

\section{Metodologia}

De acordo com o site da SEDU, ${ }^{3}$ o Ensino Médio no Estado é constituído de 280 escolas, sendo 252 no espaço urbano e 28 no espaço rural. No espaço urbano há 118.897 alunos e, no rural, 3.397 estudantes, totalizando 122.294 alunos. Quando consideramos o total de escolas localizadas na cidade de Vitória, existem 13 escolas de Ensino Médio da rede estadual. Essas escolas estão situadas em diferentes bairros. As escolas, suas localidades ${ }^{4}$ e o número de alunos estão alocados na tabela 1:

\footnotetext{
${ }^{2}$ Este artigo resulta de uma dissertação de mestrado defendida no Programa de Pós-Graduação em Educação Física da Universidade Federal do Espírito Santo (BUNGENSTAB, 2013).

${ }^{3}$ Essas informações foram retiradas do site da SEDU (www.sedu.es.gov.br) no primeiro semestre de 2013.

${ }^{4}$ Reconhecemos, na esteira de Domingues (1994), que o conceito de periférico e central tem sido banalizado nos últimos anos. A noção de central e periférico usada aqui tem o sentido menos geográfico e mais sociológico. Assim, a escolas periféricas referem-se aquelas que se situam em regiões socioeconomicamente carentes (mesmo estando, muitas vezes, localizadas geograficamente próximas ao centro da cidade). Já as escolas centrais são aquelas que estão localizadas em regiões mais desenvolvidas (mesmo algumas estando geograficamente distante do centro da cidade).
} 
Tabela 1- Localidade das escolas de Ensino Médio e seus alunos

\begin{tabular}{lcl} 
Escola de Ensino Médio & Localidade (região) & Número de alunos \\
\hline Escola 1 & Central & 736 \\
\hline Escola 2 & Periférica & 732 \\
\hline Escola 3 & Central & 339 \\
\hline Escola 4 & Periférica & 194 \\
\hline Escola 5 & Periférica & 210 \\
\hline Escola 6 & Central & 1.112 \\
\hline Escola 7 & Periférica & 578 \\
\hline Escola 8 & Central & 814 \\
\hline Escola 9 & Central & 1.291 \\
\hline Escola 10 & Central & 1.769 \\
\hline Escola 11 & Periférica & 869 \\
\hline Escola 12 & Periférica & 1.062 \\
\hline Escola 13 & Central & 1.018
\end{tabular}

\section{Seleção dos sujeitos}

A escolha das escolas (e dos sujeitos) a serem pesquisadas teve como pré-requisito que as mesmas fossem de Ensino Médio, instituições públicas e que estivessem situadas na Capital do Espírito Santo. A escolha pela cidade de Vitória é justificada pelo fato de que se trata da capital do Estado do Espírito Santo, possuindo, assim, importante influência no que tange ao sistema educacional desse Estado. Já a opção pelas escolas supracitadas se deu pela possibilidade de realizar o questionário aberto em todas elas (13 escolas). O questionário aberto foi aplicado em uma turma do segundo ano do Ensino Médio de cada escola, totalizando 13 turmas. A opção por estudantes do segundo ano levou em consideração o fato de que eles se encontram no meio do percurso desta etapa de ensino. Para a escolha da turma dentro de cada escola, optou-se por aplicar o questionário naquelas que possuíam o maior número de alunos(as).

Com a aplicação do questionário, a intenção foi a de mapear as práticas corporais que os jovens têm acessado dentro e fora da escola, bem como a relação que eles tecem com seus respectivos colégios. Juntando os questionários de todas as escolas, obtivemos 276 questionários. Essa primeira incursão ocorreu durante todo o segundo semestre de 2012. O questionário aberto aqui se apresenta como uma técnica de investigação e, segundo Gil (2008), é constituído por questões que procuram entender sobre sentimentos, opiniões, valores, crenças e expectativas. Lançamos mão, ainda, de Macedo (2000) quando ele fala sobre a relevância do questionário aberto nas pesquisas qualitativas dizendo que este é uma importante ferramenta em prol de uma busca maior na riqueza dos dados.

As perguntas gerais no questionário aplicado aos estudantes foram relativas à idade, ao gênero, trabalho e relacionamento (estado civil). No que tange a escola, perguntamos aos jovens se eles mudariam algo em seus respectivos colégios. Especificamente sobre a disciplina de educação física e as práticas corporais, as perguntas foram: sobre aprendizagem nas aulas de educação física (se gostam da mesma); o local que os jovens preferem realizar práticas corporais; se frequentam as aulas de educação física e se realizam alguma prática corporal fora da escola.

\section{A visão que os estudantes possuem de suas escolas}

Dos 276 jovens que responderam o questionário aberto, 85\% tinham entre 15 e 17 anos, $13.5 \%$ entre 18 e 21 e $1.5 \%$ não responderam a idade. Percebe-se que $13.5 \%$ 
apresentaram defasagem em relação à etapa de ensino na qual eles estão. Em relação ao sexo, $57 \%$ eram do feminino e $43 \%$ do masculino. Em relação ao trabalho, $46 \%$ dos jovens trabalham e $54 \%$ disseram que não trabalham. Sobre relacionamentos, $73.5 \%$ dos jovens estavam solteiros, $25.7 \%$ estavam namorando e dois jovens são casados.

De todas as escolas visitadas, a escola 1 se encontrava em reforma; sendo assim, as aulas de educação física estavam sendo realizadas dentro da sala de aula. Fato parecido ocorreu nas escolas 4, 5 e 8: por falta de um ambiente adequado (quadra poliesportiva), as aulas tinham que ser realizadas em sala ou no pátio. Leão, Dayrell e Reis (2011), ao realizarem estudo com jovens das escolas de Ensino Médio do Estado do Pará, perceberam que muitos jovens reclamavam das condições em que suas escolas se encontravam. Os questionamentos se referiam à falta de limpeza, falta de climatização nas salas e a não utilização adequada do espaço da escola (como laboratórios e bibliotecas). Ainda segundo os autores (2011, p. 263):

O problema de infraestrutura escolar parece ser recorrente em muitos estados brasileiros. Em parte, isso se deve à resistência a ampliar os gastos com a educação e a opção por uma política de financiamento focalizada no ensino fundamental iniciada nos anos 1990 e que perdurou até 2007.

Considerando a estrutura das escolas investigadas, o questionário perguntava aos jovens se eles mudariam algo em seus colégios. Nesse sentido, $67.7 \%$ alunos disseram que sim, já $24.6 \%$ disseram que não mudariam nada e $7.6 \%$ não responderam. Um jovem da escola 11 disse: "Mudaria a segurança. Muitas coisas acontecem como, consumo de drogas etc...". Uma aluna da escola 8, quando perguntada se mudaria algo, disse: "Sim. Porque não tem quadra.". Um aluno da escola 12 disse: "Colocaria mais esportes diferentes na escola, e ter mais aula de educação física por semana. Porque eu gosto de praticar esporte". Não é só a parte da sua estrutura física que a escola é vista pelos jovens. Eles também voltam seus olhares para outros aspectos que não deixam de ser menos importantes. Um deles refere-se à questão da segurança e o corpo pedagógico da escola.

Dos $67.7 \%$ alunos(as) que mudariam algo na escola, a metade disse que mudaria os professores, os pedagogos e coordenadores, alegando que esses sujeitos não cumprem suas funções. Na visão deles(as), alguns desses profissionais não dão boas aulas e também não se relacionam bem com os alunos. Uma aluna da escola 1 disse que mudaria a "Estrutura, as atividades, a direção, pois com essas e outras mudanças ficaríamos mais motivados a vir à escola". Assim, esses jovens disseram que, para a escola melhorar, teria que haver uma mudança no corpo docente. Outra aluna da escola supracitada disse o seguinte: "[...] há muita falta de respeito e compreensão.". Um aluno da escola 2 disse que mudaria “[...] porque é uma escola desorganizada e esquecida pelo governo". Em outro contexto, Leão, Dayrell e Reis (2011) concluíram que os alunos apontam os aspectos negativos do professor quando a relação existente é marcada pela falta de diálogo. Com as respostas dos alunos(as) aqui pesquisados, percebe-se que eles, também, apontam os aspectos negativos não só do professor, mas da escola de um modo geral (segurança, estrutura física, etc.) quando a relação não atende as suas expectativas.

As mudanças relacionadas ao corpo pedagógico devem ser levadas em consideração, pois como destaca Krawczyk (2011), o sentido da escola para os estudantes está ligado não apenas pela integração escolar do aluno, mas, também, na sua identificação com os professores. A atitude do docente, seu modo de ensinar, sua capacidade de estimulação e diálogo, segundo a autora, pode despertar o interesse por parte dos estudantes. Ainda de acordo com Krawczyk (2011, p. 767): 
O que no passado foi considerado como transmissão de regras e valores da sociedade, hoje deve ser visto como possibilidade de reflexão, comunicação e redefinição das regras e valores estabelecidos [...] um desafio desse tipo não pode ser encarado numa sociedade hostil em relação à juventude, nem por meio de projetos individuais de uma escola, de um professor.

Uma das principais respostas dos alunos diz respeito às regras que são impostas pelos professores e coordenadores, sem ao menos, na visão deles, haver o diálogo. Uma aluna da escola 13 disse: "[...] mudaria sim, eu tornaria a escola um lugar mais livre". Um aluno ainda da mesma escola disse que mudaria "[...] pois tem coordenadores que não têm capacidade em lidar com o adolescente. Mudaria a merenda da escola e o sistema de ventilação na sala". Outra aluna da escola 10 disse: "mudaria o desenvolvimento das aulas para que os alunos e professores se relacionem melhor, porque tem muitos professores que são muito parados". Os alunos se mostram muitas vezes insatisfeitos com o tratamento que lhes é dado. As 13 escolas pesquisadas (já que em todas, sem exceção, parte dos seus alunos disseram querer mudar algo) e os próprios jovens, precisam se atentar para essas reclamações que atingem suas estruturas físicas, bem como aquelas reclamações a respeito dos comportamentos dos indivíduos que vivenciam esse espaço, sejam eles alunos e/ou professores.

Segundo Abramovay e Castro (2003, p. 279), o ensino de qualidade não significa apenas o bom trabalho docente em relação ao aluno. Ele também diz respeito a uma escola com boa infraestrutura, instalações e recursos que, juntos, são suportes importantes para o processo de ensino e aprendizagem.

Em primeiro lugar, porque uma escola ampla, organizada, equipada e limpa cria um ambiente favorável ao trabalho, motivando a equipe escolar em suas atividades cotidianas. Segundo, porque um ambiente confortável beneficia o aprendizado dos alunos, na medida em que oferece os recursos e as condições para que os jovens desenvolvam seu potencial.

As mudanças nas escolas seriam em relação à estrutura física do espaço, que não é agradável e não satisfaz as necessidades juvenis dentro desse ambiente (por exemplo, falta de espaço para práticas esportivas, cadeiras e mesas desconfortáveis, em mau estado e reformas na arquitetura da escola sem reformas), a falta de segurança e, também, em relação aos professores, dizendo que muitos deles não sabem trabalhar e lidar com o jovem dentro da sala de aula. Visto isso, como estão sendo tecidas as tramas entre os estudantes e as práticas corporais dentro (e fora) deste espaço escolar?

\section{Mapeando a juventude e as práticas corporais (extra) escolares}

A relação que a escola estabelece com os jovens estudantes torna-se aspecto importante de análise, já que esses indivíduos trazem consigo modos de vida do cotidiano exterior ao muro escolar que constituem sua cultura, como os seus relacionamentos com as práticas corporais. Especificamente em relação à educação física escolar, no questionário aplicado, perguntou-se aos jovens se eles frequentam as aulas, o que eles aprendem e se gostam da mesma. Dos 276 alunos questionados, 95\% frequentam as aulas de educação física e apenas 5\% disseram não frequentar. Desses últimos, 2,5\%, apesar de não frequentarem as aulas, gostam da disciplina. Uma aluna da escola 6 que não frequenta as aulas, quando perguntada se gostava da educação física, respondeu: "Sim, mas nessa escola não tive boas aulas de educação física. A professora não sabe dividir a quadra e o tempo com os meninos, que só querem jogar futebol". Outra aluna, da escola 12, disse: "Gosto, porque eu não faço nada, fico na sala dormindo ou conversando com amigos.". Na pergunta sobre o que aprendem nas aulas de educação física, temos a seguinte situação (tabela 2): 
Tabela 2 - conteúdo aprendido pelos alunos conforme suas indicações

\section{Conteúdo}

Várias atividades (esportes, jogos,

brincadeiras e aprendizagem sobre o

corpo humano)

\begin{tabular}{cc}
\hline Esportes coletivos (regras e modalidades) & $35.5 \%$ \\
\hline Não sabe & $0.7 \%$ \\
\hline Nada & $24.2 \%$ \\
\hline Coisas chatas & $0.7 \%$ \\
\hline Dança & $7.6 \%$ \\
\hline Nada que ele já não saiba & $0.3 \%$ \\
\hline Aprende a odiar esportes & $0.3 \%$ \\
\hline Não responderam & $3.9 \%$ \\
\hline Total & $100 \%$
\end{tabular}

Os dados acima revelam que o esporte aparece como conteúdo predominante nas aulas de educação física no Ensino Médio. Fato que vai ao encontro as recentes pesquisas realizadas por Cordovil et al. (2015) e Brandolin et al. (2015) que também notaram a forte presença do esporte nesta etapa de ensino. No entanto, além de constatar que o esporte ainda predomina nas aulas (35.5\% das respostas), a tabela acima demonstra que os jovens pesquisados dizem também nada (24.2\%) aprenderem nas aulas. Nesse sentido, num universo de $100 \%$ dos alunos, 59,7\% disseram que: ou aprendem esportes ou não aprendem nada.

Durante a visita à escola 12, após aplicar o questionário aberto com uma turma de segundo ano, acompanhamos uma aula de educação física dessa turma. A escola possui duas quadras descobertas, uma para prática de vôlei e outra para prática de futsal, além de espaços arborizados. Durante a aula, a maioria dos alunos (as) se dividiu entre as duas quadras, três alunos ficaram praticando o slackline entre duas árvores e algumas poucas meninas ficaram sentadas lendo revistas de moda. O professor apenas liberou as bolas e nem sequer ficou na quadra vigiando os alunos, que, em sua maioria, pareciam estar se divertindo durante a aula, mesmo que o professor nada estivesse ensinando para eles. Qual saber estava impregnado ali?

Charlot $(2000,2013)$ nos mostra que a discussão a respeito da relação com o saber sempre aparece quando existem sujeitos que estão dispostos a aprender, ao passo que outros não manifestam esse mesmo desejo. Como visto acima, dos 262 jovens que frequentam as aulas, 69\%, disseram aprender alguma coisa, mesmo que essa seja "coisa chata". Um aluno da escola 10, ao ser perguntado sobre o que aprende nas aulas disse: "aperfeiçoar a prática dos meus dribles". Uma aluna da escola 9 disse: "aprendo a jogar vôlei e futsal". Outro aluno da escola 7 disse que as aulas de educação física propiciam a ele: "melhorar meu condicionamento físico". Entre as atividades que esses jovens disseram aprender, foram relatados diversos conteúdos que fazem parte da disciplina de educação física, como jogos e brincadeiras, esportes, danças e aprendizagens sobre o corpo humano. Uma aluna da escola 13, quando perguntada sobre o que aprende nas aulas de educação física, disse que aprende: "regras, como jogar e se comportar". Outro jovem da mesma sala disse aprender: "regras dos esportes, aprender a jogar esportes coletivos diferentes". À semelhança do que Schneider e Bueno (2005) identificaram em outro contexto, também constatamos que mais da metade dos alunos conseguiram definir os saberes que a disciplina de educação física os proporcionou.

No entanto, observamos uma diferença da relação que esses jovens possuem com o mesmo saber. Nessa mesma turma (da escola 13), uma aluna disse não aprender nada nas aulas, ao passo que alguns alunos dizem aprender conteúdos da disciplina. Existem diferenças que são apresentadas pelos jovens diante do saber e que não se justificam, apenas, em função 
de alguma desmotivação do aluno ou, então, pelo fato de ele ser preguiçoso. Trata-se, conforme argumenta Charlot (2000), da relação entre o indivíduo e aquilo que tentam ensinálo. Como vemos, em $24.2 \%$ respostas, os alunos(as) relataram que não aprendem nada. $\mathrm{O}$ conteúdo da disciplina, ao mesmo tempo em que faz sentido para alguns jovens, pode não fazer sentido para outros (como no caso do ensino dos esportes). Assim, não aprender nada não significa que o professor nada ensina, mas sim, que aquilo que ele ensina pode não estar fazendo sentido para a aluna.

Em relação às práticas corporais (esportivas ou não) realizadas no ambiente fora da aula de educação física, perguntamos se os jovens as praticavam. Obtivemos como resposta que $65 \%$ praticam, $33 \%$ disseram que não praticam e $2 \%$ não responderam. Dentre as atividades que mais apareceram, destacamos os esportes coletivos, esportes radicais (como skate e surf), lutas, academia, corrida e dança. Um aluno da escola 1 disse praticar judô em uma academia; quando perguntado o que essa atividade proporciona a ele, ele respondeu: "porque eu gosto, tenho mais respeito com todos". Outro aluno da escola 8 disse que pratica o surf aos finais de semana pela manhã e futebol aos sábados à tarde, sempre com os amigos; sobre o que essas atividades proporcionam, o jovem disse: "me faz sentir melhor no meu desenvolvimento corporal e pelo prazer de fazê-los". Pereira e Silva (2004, p. 73) caracterizaram as atividades esportivas como sendo dominantes da cultura escolar e da cultura extra-escolar:

[...] considerando as práticas culturais dos adolescentes do EM do RS, classificou os esportes de quadra, como basquete e o handebol como elementos característicos da cultura escolar; o futsal e as formas gímnicas como caminhadas, como atividades culturais comuns ao ambiente escolar e não-escolar; e as lutas (artes marciais), como o taekwondo, as danças gauchescas e o pádel ${ }^{5}$ como formas de cultura física extraescolar.

Do mesmo modo que assinalado por Pereira e Silva (2004), notamos que os jovens aqui pesquisados também demonstram que os esportes estão presentes tanto na cultura escolar como nos espaços fora da escola. No entanto, como nos mostra a tabela 2, os esportes que dominam a cultura escolar são os esportes coletivos. Já em relação às práticas corporais realizadas fora da escola, além dos esportes coletivos, os jovens relataram aprender outros tipos de esportes como aqueles de cunho radicais e os esportes individuais. Como a educação física escolar poderia abarcar as práticas corporais e os diferentes esportes que são experimentados pelos jovens fora da escola? De acordo com Pereira e Silva (2004),

[...] para o esporte e outras formas culturais terem um maior aproveitamento é preciso romperem as amarras das suas formas objetivas de cultura não-escolar e, necessariamente, escolarizar-se. A escolarização implica que na EF se desenvolvam aulas com esporte, e não apenas aulas de esporte. Deve-se, pois, educar a partir do esporte enquanto esporte, mas desenvolvido com a necessária objetividade pedagógica, ainda que suas regras e rituais sejam geralmente quebrados escolarmente, em função da quantidade de praticantes e tempo disponível [...] A escolarização do esporte, da ginástica e da dança, como conteúdos de ensino na EF, tendo o caráter dialético de mediação e de finalidade, necessita operacionalizar-se com o devido tratamento pedagógico-didático, como se dá com as outras disciplinas escolares (PEREIRA; SILVA, 2004, p. 75).

Chicati (2000) demonstrou que os alunos do Ensino Médio deixam claro que gostam de aprender sobre esportes; no entanto, de vez em quando também gostariam de aprender e

\footnotetext{
5 Trata-se de uma prática corporal de equipe que utiliza raquetes e bolas próprias. Para mais informações, acessar: https://www.fppadel.pt/
} 
experimentar outros conteúdos. A mídia, as academias, os clubes e as escolinhas de esporte estão, cada vez mais, oportunizando para os jovens experiências de práticas corporais fora da escola. Como visto na tabela 2, apenas os esportes coletivos e a dança aparecem como atividades realizadas, pelos jovens, tanto fora como dentro da escola. Todas as outras atividades que eles praticam fora da escola não são experimentadas dentro da mesma. Essa relação entre os que os jovens praticam dentro com aquilo que realizam fora da escola pode suscitar reflexão a respeito do que está em voga em relação às práticas corporais no cotidiano juvenil.

Os jovens na sociedade atual se movem rapidamente, dando dinamicidade ao processo de aprendizagem e apropriação. De acordo com Carrano (2011), a escola, com suas disciplinas (como a educação física), ainda se apresenta como uma instituição futurista, ou seja, possui seus sentidos de aprendizagem voltados para o futuro e isso seria um dos principais motivos das insatisfações dos jovens estudantes, sobretudo quando esses passam a optar e legitimar mais as aprendizagens e apropriações advindas de fora do contexto institucionalizado da escola. Perguntamos aos 276 jovens se eles preferem realizar práticas corporais dentro ou fora da escola e tivemos o seguinte (tabela 3):

Tabela 3 - local de preferência para a prática corporal

Local de preferência

Número de Alunos

\begin{tabular}{cc}
\hline Dentro da escola & $13.7 \%$ \\
\hline Fora da escola & $51.4 \%$ \\
\hline Dentro e Fora & $24.6 \%$ \\
\hline Nenhum dos dois lugares & $1 \%$ \\
\hline Não responderam & $9 \%$ \\
\hline Total & $100 \%$
\end{tabular}

Percebe-se, com o quadro acima, que $51.4 \%$ dos jovens preferem realizar práticas corporais apenas fora da escola e $13.7 \%$ tem preferência por praticar a mesma apenas dentro do ambiente escolar. Entre as justificativas pela preferência fora, um aluno da escola 12 disse: "fora, pois a escola não oferece condições para praticar dentro". Outro aluno, da mesma escola, disse que prefere "fora, porque você tem mais liberdade." Um aluno da escola 1 disse que prefere: "fora da escola, porque tem mais opções." Uma aluna da escola 6 disse que prefere praticar "fora, pois na escola não tem atividades que me identifico." Stech (2000), após analisar as falas de alguns jovens europeus em relação ao saber, as separou em três categorias: aprendizagens ligadas à vida cotidiana; aprendizagens afetivas/éticas/morais; e aprendizagens escolares. Os esportes e as atividades culturais foram classificados, por ele, como aprendizagens do cotidiano. Assim, no contexto de sua pesquisa, foi constatado que as aprendizagens esportivas e culturais ligadas à vida cotidiana são predominantes no que tange ao processo de aprendizagem dos jovens europeus se comparadas àquelas aprendizagens escolarizadas. Neste artigo, as práticas corporais (e os esportes) aparecem como saber da escola (personificadas por meio da disciplina de educação física); no entanto, assim como nos estudos de Stech (2000), elas ganham destaque, também, quando relacionadas com o mundo cotidiano de fora da escola. Será que o mundo fora da escola está mais atrativo que o mundo escolar?

Os jovens aprenderam muitas coisas antes de entrar na escola e continuam a aprender, fora da escola, ainda que freqüentem a escola - coisas essenciais para eles ('a vida'). Eles já construíram relações com 'o aprender', com aquilo que significa aprender, com as razões pelas quais vale a pena aprender, com aqueles que lhes ensinam as coisas da vida. Portanto, sua (s) relação (ões) com o (s) saber (es) que eles encontram na escola, e sua (s) relação (ões) com a própria escola não se 
constroem a partir do nada, mas a partir de relações com o aprender que eles já construíram. Não se vai à escola para aprender, mas sim para continuar a aprender (CHARLOT, 2000, p. 149).

Quando perguntamos aos jovens se eles preferem realizar suas práticas corporais dentro ou fora da escola, esperávamos que os alunos optassem responder dentro ou fora, já que a própria pergunta induzia a essa escolha. No entanto, surpreendeu o número de estudantes que responderam "dentro e fora": $24.6 \%$ jovens. A presença do "e" trás consigo um significado que devemos considerar. Ele nos mostra que vários alunos(as) valorizam tanto o que é praticado na escola, como o que é praticado fora dela. Eles deixam a entender que ambos os locais geram momentos de aprendizagens, de saberes e de experiências das práticas corporais. Talvez, como ressaltou Charlot (2000, 2013), esses jovens tenham encontrado uma saída que parece conseguir tirar proveito das especificidades e heterogeneidades (mesmo que em meio às tensões existentes) que cada ambiente tem a oferecer em relação às práticas corporais.

Os jovens, de fato, tratam os diferentes saberes e métodos (sejam eles dentro da escola, na internet, revistas ou na cultura da rua) de aprendizagem hoje existentes de forma múltipla e fluida, dando validade para todas elas. A disciplina de educação física, nesse momento, precisa buscar maneiras atrativas para que seu espaço seja valorizado no que tange às práticas corporais para os jovens? Vimos que $61 \%$ dos jovens entrevistados gostariam de experimentar alguma prática corporal que ainda não tiveram condição de realizar. Seria esse o momento ideal para a escola oportunizar essas experiências e saberes para esses jovens alunos?

A falta de experimentação de diferentes práticas corporais no seio escolar não pode ser traduzida pela incapacidade docente. É preciso entender que essa discussão, muitas vezes, perpassa a decisão do professor. Exemplo disso aconteceu na visita à escola 8. Essa escola não possui quadra e o espaço onde aconteciam as aulas de educação física era pequeno. No entanto, a professora conseguia ensinar algumas práticas corporais para os jovens, como por exemplo, a dança. Ao conversar com a professora sobre as práticas corporais cotidianas, ela me relatou que há meses havia feito um pedido a Secretaria de Educação solicitando cordas e elásticos para realizar novas atividades com os alunos(as) e ainda estava aguardando o material sem saber em qual data chegaria. Esse exemplo, da falta de materiais, revela a dificuldade que os bons profissionais têm em produzir e montar uma aula de qualidade. Assim, a culpa não pode ser dirigida toda ao professor ou ao aluno, mas sim, fazer com que todos os integrantes nesse processo (principalmente a escola) se esforcem para que os saberes, quando relacionados às práticas corporais, sejam importantes no seio da escola.

\section{Considerações finais}

Os resultados apresentaram uma problemática que trata da relação que os jovens possuem com suas práticas corporais realizadas dentro e fora da escola. A hipótese era a de que as práticas corporais realizadas fora da escola estariam mais presentes na vida dos jovens, pois em seus cotidianos eles têm a possibilidade de experimentar e vivenciar as mais diversas práticas corporais. A escola, por sua vez, permeada de ritos e regras (DUBET, 1994), estaria se tornando desagradável para a juventude no que se refere às práticas corporais, já que a disciplina de educação física não estaria dando conta de oportunizar aos jovens diferentes experiências além, principalmente, do ensino dos esportes coletivos.

De fato, esse trabalho deu pistas de que os jovens do Ensino Médio se mostram, muitas vezes, críticos as aulas de educação física que lhes são dadas, reconhecendo ainda que, fora da escola, existem mais opções. No entanto, os resultados demonstraram que, apesar de reconhecerem falhas em relação às práticas corporais realizadas dentro da escola, eles não 
delegam às práticas corporais de fora da escola o título de salvadoras ou suficientes. Para Charlot (2013), a instituição escolar, por meio da linguagem, tem a capacidade de gerar novos objetos e pensamentos diferentes daqueles que são gerados na vivência cotidiana. Os jovens estudantes parecem corroborar com essa perspectiva de Charlot considerando todos os espaços válidos para a realização de práticas corporais. Seja esse espaço institucionalizado ou não.

Os jovens pesquisados procuram tirar proveito tanto das práticas corporais realizadas dentro da escola (por meio da educação física ou não) como aquelas que eles realizam fora da escola por conta própria. Não foi vista uma unanimidade de uma em relação à outra e, sim, uma relação horizontal no sentido de reconhecer que ambos os espaços podem oportunizar experiências e conhecimentos interessantes para a juventude. No entanto, faltam pesquisas de ensino, faltam estudos sobre o desenvolvimento do pensamento do jovem; faltam ações governamentais (MELO; FERRAZ, 2007) para entendermos melhor a relação da juventude contemporânea com suas práticas corporais (extra) escolares.

\title{
BODY PRACTICES IN SECONDARY EDUCATION SCHOOLS LOCATED IN VITÓRIA/ESPÍRITO SANTO
}

\begin{abstract}
The article discusses the relationship that high school students have with the body practices performed by them in and out of school. For this, the research involved all state schools that offer high school in the city of Vitória, capital of Espírito Santo. The application of a questionnaire provided evidence of how young people be related to knowledge of physical education and different body practices. We conclude that young people show that school corporal practices are below their expectations. However, it was noted that there is no devaluation of these practices from those that are held outside of school.
\end{abstract}

Keywords: Body practices. High School. Young.

\section{PRÁCTICAS CORPORALES EN ESCUELAS DE EDUCACIÓN SECUNDARIA UBICADAS EN VITÓRIA/ESPÍRITO SANTO}

\section{Resumem}

El artículo analiza la relación que los jóvenes de la escuela secundaria tejen con las prácticas corporales realizados por ellos dentro y fuera de la escuela. Con este fin, la investigación involucró a todas las escuelas estatales que ofrecen la etapa secundaria en la ciudad de Vitória, capital de Espírito-Santo. La aplicación de un cuestionario proporcionado evidencia como los jóvenes se relacionan con el conocimiento de la educación física y las diferentes prácticas corporales. Llegamos a la conclusión de que los jóvenes muestran que las prácticas corporales escolares están, muchas veces, por debajo de sus expectativas. Sin embargo, se observa, también, que no hay una devaluación de estas prácticas de las que se llevan a cabo fuera de la escuela.

Palabras-clave: Prácticas corporales. Escuela Secundaria. Jóvenes. 


\section{Referências}

ABRAMO, H. Considerações sobre a tematização social da juventude no Brasil. In: PERALVA, Angelina Teixeira; SPÓSITO, Marília Pontes (Org.). Revista Brasileira de Educação, n. 5-6, p. 25-36, maio/dez. 1997.

ABRAmovaY, M.; CAStro, M. G. (Org). Ensino Médio: Múltiplas Vozes. Brasília: UNESCO; MEC, 2003.

ALMEIDA JR., A. S. et al. Conhecimentos de educação física. In: SECRETARIA DE EDUCAÇÃO BÁSICA/MEC (Org.). Orientações curriculares para o ensino médio. Brasília: Ministério da Educação, Secretaria de Educação Básica, 2006.

BARDIN, L. Análise de conteúdo. Lisboa: Edições 70, 1988.

BERMAN, M. Tudo que é sólido se desmancha no ar: a aventura da modernidade. São Paulo: Companhia das Letras, 2007.

BRANDOLIN, F; KOSLINSKI, M.C; SOARES, A. J. A percepção dos alunos sobre a educação física no ensino médio. Revista de Educação Física, v. 26, n.4, p.601-610, 2015.[Disponível em: <http://periodicos.uem.br/ojs/index.php/RevEducFis/article/view/29836>

Acesso em: 14 fev. 2016.

BUNGENSTAB, G. C. Cultura jovem na cidade de Vitoria/ES: as práticas corporais juvenis e sua relação com a educação física escolar. 2013. 163 f. Dissertação (Mestrado em Educação Física) - Departamento de Educação Física, UFES, Vitória, 2013.

CARRANO, P. C. R. O ensino médio na transição da juventude para a vida adulta. In: Ferreira, Cristina A. et al.(Org.). Juventude e iniciação científica: políticas públicas para o ensino médio. 1ed. Rio de Janeiro: EPSJV, UFRJ, 2011.

CHARLOT, B. Da relação com o saber às práticas educativas. São Paulo: Cortez, 2013.

2000.

. Da relação com o saber: elementos para uma teoria. Porto Alegre: Editora Artmed,

CHICATI, K.C. Motivação nas aulas de Educação física no ensino médio. Revista de Educação Física, v. 11, n. 1, p. 97-105, 2000. [Disponível em: <http://periodicos.uem.br/ojs/index.php/RevEducFis/article/download/3799/2611> Acesso em: 4 nov. 2013.

CORDOVIL, A. P. R; GOMES, C; MOREIRA, E; SILVA, M. S. O espaço da educação física na escola: um estudo sobre os conteúdos das aulas de ensino médio. Revista Pensar a Prática, v. 18, n. 4 p. 834-847, out./dez. 2015. Disponível em: <https://www.revistas.ufg.br/index.php?journal=fef\&page=article\&op=view\&path\%5B\%5D $=34352 \&$ path\%5B\%5D=19783> Acesso em: 15 fev. 2016 .

DAYRELL, J. O jovem como sujeito social. Revista Brasileira de Educação. Rio de Janeiro. n. 24. p. 4-13, dez, 2003. 
DOMINGUES, A. (Sub)úrbios ou (sub)urbanos - o mal estar da periferia ou a mistificação dos conceitos? Revista da faculdade de Letras, Porto, v. X/XI, p. 5-18, 1994.

DUBET, F. Sociologia da Experiência. Lisboa: Instituto Piaget, 1994.

FENSTERSEIFER, Paulo Evaldo. O que significa aprender no âmbito da cultura corporal de movimento? Atos de pesquisa em Educação, v.7. n. 2, p. 320-328, maio/ago. 2012. Disponível em: <http://proxy.furb.br/ojs/index.php/atosdepesquisa/article/view/3152/1987> Acesso em: 5 out. 2015.

GIL, A. C. Como elaborar projetos de pesquisa. São Paulo: Atlas, 2008.

KRAWCZYK, N. O Ensino Médio no Brasil. Ação educativa: São Paulo, 2009.

- Reflexão sobre alguns desafios do Ensino Médio no Brasil hoje. Cadernos de Pesquisa, São Paulo. v. 41, n. 144 set/dez. 2011.

LAZZAROTTI FILHO A. et al. O termo "práticas corporais" na literatura cientifica brasileira e sua repercussão no campo da educação física. Revista Movimento, Porto Alegre, v. 16, n. 1, jun. $2009 . \quad$ Disponível em: <http://seer.ufrgs.br/index.php/Movimento/article/view/9000/7513>

LEÃO, G; DAYRELL, J; REIS, J. B. Jovens olhares sobre a escola do ensino médio. Caderno Cedes, Campinas, vol. 31, n. 84, 2011. Disponível em: <http://www.cedes.unicamp.br> Acesso em: 12 fev. 2012.

MACEDO, R. S. A etnopesquisa crítica e multirreferencial nas ciências humanas e na educação. Salvador: Edufba, 2000.

MELO, R. Z; FERRAZ, O. L. O novo ensino médio e a educação física. Revista Motriz, v. 13, n. 2 p. 86-96, $2007 . \quad$ [Disponível em: <http://www.periodicos.rc.biblioteca.unesp.br/index.php/motriz/article/download/753/756> Acesso em: 3 set. 2014.

PAIS, J. M. Culturas juvenis. Lisboa: Imprensa Nacional Casa da Moeda, 1993.

PEREIRA, F. M; SILVA A. C. Sobre os conteúdos de Educação física no ensino médio em diferentes redes educacionais do Rio Grande do Sul. Revista de Educação Física, v. 15, n. 2, p. 67-77, 2004. [Disponível em: <http://periodicos.uem.br/ojs/index.php/RevEducFis/article/viewArticle/3423> Acesso em: 19 dez. 2015.

SILVA, A. M. et al. Corpo e experiência: para pensar as práticas corporais. In: FALCAO, J. L.; SARAIVA, M (Org.). Práticas corporais no contexto xontemporâneo: (in)tensas Experiências. Florianópolis: Copiart, 2009.

SCHNEIDER, O; BUENO, J. G. S. A relação dos alunos com os saberes compartilhados nas aulas de educação física. Revista Movimento, Porto Alegre, v. 11, n. 1 p. 23-46, jan./abr. 
2005. Disponível em: <http://seer.ufrgs.br/Movimento/article/view/2860> Acesso em: 25 fev.2012.

STECH, S. O que significa aprender para os alunos tchecos? Balanços do saber no início dos anos 90. In: CHARLOT, B. (Org.). Da relação com o saber: elementos para uma teoria. Porto Alegre: Editora Artmed, 2000.

TRIVIÑOS, A. N. S. Introdução à pesquisa em Ciências Sociais: a pesquisa qualitativa em educação. São Paulo: Atlas. 1987.

Recebido em: 14/12/2015

Revisado em: 10/02/2016

Aprovado em: 29/02/2016

Endereço para correspondência:

gabrielcarv@msn.com

Gabriel Carvalho Bungenstab

Universidade Federal de Goiás

Faculdade de Educação Física e Dança

Avenida Esperança, s/n

Campus Samambaia

74690-900 - Goiânia, GO - Brasil 